\title{
Predictive accuracy of APACHE-II for mortality in poly trauma patients.
}

1. MBBS

Medical Officer

Lahore General Hospital, Lahore.

2. FCPS

Assistant Professor Surgery

Govt Teaching Hospital Shahdara/ FJMU Lahore.

3. FCPS

Assistant Professor Surgery

DHQ Gujranawala.

4. FCPS

Assistant Professor Surgery

Govt Teaching Hospital Shahdara/

FJMU Lahore.

5. FCPS

Senior Registrar Surgery

Jinnah Hospital, Lahore.

6. MS

Consultant Surgeon

DHQ Jehlum.

Correspondence Address:

Dr. Mudassar Murtaza

Department of Surgery

Govt Teaching Hospital Shahdara/

FJMU Lahore.

339 E Block Johar Town Lahore.

drmudassirmurtaza@gmail.com

Article received on:

03/01/2020

Accepted for publication:

28/03/2020
Manzoor Qadir Joyia', Mudassar Murtaza², Mohammad Ansar Aslam³, Fakhar Irfan4, Hira Liaqat Ahmed Raza Naumani ${ }^{6}$

ABSTRACT... Objectives: The objective of our study was to find diagnostic accuracy of APACHEII score to predict mortality in poly trauma patients within first 24 hours of hospitalization. Study Design: Cross Sectional study. Setting: Department of Emergency Lahore General Hospital. Period: 25 March, 2016 to 25 September, 2016. Material \& Methods: A total of 230 patients who fulfilled inclusion criteria were enrolled in the study from emergency department of Lahore General Hospital. To calculate APACHE-II score, vital signs, blood / serum profile, GCS, age and prolong health problems were measured on patients' arrival. Patients were classified as per their APACHE-II score. After calculating APACHE-II score patients were managed according to trauma severity and followed up till 24 hours to note the in- hospital mortality. Results: Out of 230 patients, $147(63.91 \%)$ were male and $83(36.09 \%)$ were female; mean age was $38.53 \pm$ 11.67 years. Out of 230 cases, in hospital mortality occurred in $84(36.5 \%)$ while other $146(63.5 \%)$ were alive within 24 hours of admission. According to APACHE-II score, 84(36.5\%) cases had $>11.5$ score and rests of $146(63.5 \%)$ had APACHE-II $\leq 11.5$. The sensitivity, specificity, PPV, NPV and diagnostic accuracy of APACHE-II was $89.16 \%, 93.2 \%, 88.1 \%, 93.84 \%$ and $91.74 \%$ respectively. Conclusion: According to the findings of this study, we found APACHE-II highly accurate for indicating in-hospital mortality. Using APACHE-II in future we can devise an efficient treatment plan for poly trauma patients to reduce the probability of hospital mortality.

Key words: $\quad$ APACHE-II, Injury, Mortality, Prediction, Scores, Survival, Trauma.

Article Citation: Joyia MQ, Murtaza M, Aslam MA, Irfan F, Liaqat H, Naumani AR. Predictive accuracy of Apache-ll for mortality in Poly Trauma patients. Professional Med J 2020; 27(11):2314-2319. https://doi.org/10.29309/TPMJ/2020.27.11.4460

\section{INTRODUCTION}

Trauma is originated from Greek language and means wound. Poly trauma is major trauma in which more than one region of body or organ systems are involved. In major trauma injury severity score is $>15$ based on anatomical severity of injury. All over the world, about 10000 people die daily due to injury. ${ }^{1}$

WHO data published in 2017 revealed that 27081 deaths occurred in Pakistan which is $2.22 \%$ of total deaths. However according to Pakistan Bureau of statistics, 5948 trauma victims were killed and 14489 patients were injured due to traffic accidents in one year 2017-18. ${ }^{2}$

Early evaluation and treatment of serious trauma patients is a cumbersome duty and some advocate some factors can rapidly change depending on blood loss and quality of resuscitation and proposed prompt-individualized-safe management( PRISM) strategy. ${ }^{3}$

APACHE-II" Acute Physiology and Chronic Health Evaluation II" is a severity-of-disease classification system. It was designed to measure the severity of disease for adult patients admitted to intensive care units. APACHE-II score (the minimum score is 0 and maximum is 71 ) is calculated from measuring vital signs, laboratory values, Glasgow coma score, age, chronic health status of the patient and type of admission. These are measured within first day of admission. The most abnormal value is used to derive a score. It is 
reported that the APACHE-II has sensitivity and specificity of $88 \%$ and $90 \%$ respectively with an accuracy of $90 \% .{ }^{4}$ But some of the researchers do not agree and figures regarding sensitivity, Specificity and accuracy have been mentioned as low as $82.5 \%, 55.2 \%$ and $66 \%$ respectively.

The rationale of this study is to evaluate the clinical importance of APACHE-II score in poly trauma patients in terms of 24 hours in hospital outcome. Due to considerable statistics of accidents and trauma related deaths in Lahore General Hospital, we need certainty of APACHE-II scoring system to accurately predict the outcome of poly trauma patients for our own population as no local study is published and international data though gives consistent sensitivity but wide range of specificity. ${ }^{4-6}$ This study will help us for triage and to devise an efficient treatment plan for poly trauma patients to reduce the probability of hospital mortality. The objective of our research was to find diagnostic accuracy of APACHEII score in forecasting mortality in poly Trauma patients within first 24 hours of hospitalization so that the more appropriate care is administered to more serious patients.

\section{MATERIAL \& METHODS}

It was a Cross Sectional study which was conducted at emergency department of Lahore General Hospital in 6 months from March 25, 2016 to September 25, 2016. Non-probability consecutive sampling was used. We took 230 patients using sensitivity and specificity of APACHE-II 82.5\%, 55.2\% 13\% margin of error for sensitivity, respectively at $8 \%$ margin of error for specificity and 95\% confidence level using 10\% prevalence of poly trauma. ${ }^{6}$

Patients presenting in emergency department with poly trauma (as per operational definitions) aged 18-60 years of either gender were included in the study. Patients with major burn, concomitant cardiac injury and those referred to other hospitals for continuation of treatment were excluded. A total of 230 patients who fulfill selection criteria were enrolled in the study from emergency department of Lahore General Hospital. Informed consent was taken for demographic profile (name, age, gender and other necessary clinical data). To calculate APACHE-II score, vital signs, laboratory values, Glasgow coma score, age and chronic health points was measured on patients arrival. Patient was classified as per their APACHEII score. After calculating APACHE-II score patient was managed according to trauma severity and followed up till 24 hours to note the in hospital mortality. All the data was recorded on a Performa by researcher himself. Data was entered and analyzed through SPSS version 20 .

Frequency and percentages were calculated for all qualitative variables like gender and in-hospital outcome (alive/mortality) on both APACHE-II score and actual outcome. Mean \pm standard deviation was calculated for all quantitative variables like age and duration of injury and APACHE-II score. True positive was labeled if APACHE-II > 11.5 and patient dies within 24 hours. False negative was labeled if APACHE-II $\leq 11.5$ and patient dies within 24 hours. False positive was labeled if APACHEII $>11.5$ and patient survives within 24 hours. True negative was labeled if APACHE-II $\leq 11.5$ and patient survives within 24 hours. $2 \times 2$ tables were made and sensitivity, specificity, positive and negative predictive values and accuracy was calculated. Data was stratified by gender, age, duration of injury ( $<2$ hours, $2-4$ hours and more than 4 hours). Post stratification chi square test was applied to compare in hospital outcome and APACHE-II score. P- Value $\leq 0.05$ was considered as significant.

\section{RESULTS}

The mean age of patients was $38.53 \pm 11.67$ years with age range of 42 years (minimum and maximum age was 18 and 60 years).There were $131(56.96 \%)$ cases $18-40$ years old and $99(43.04 \%)$ patients were 41-60 years of age. There were $147(63.91 \%)$ male and $83(36.09 \%)$ were female patients.

The mean duration of injury was $4.64 \pm 3.76$ hours with minimum and maximum duration of 1 and 16 hours. A total of $24(10.43 \%)$ cases had injury since $<2$ hours, 132(57.39\%) cases had injury since $2-4$ hours and $74(32.17 \%)$ cases had injury more than 4 hours. The mean APACHE 
II score was $18.20 \pm 17.01$ with minimum and maximum score of 0 and 71 .Out of 230 cases in hospital mortality occurred in $84(36.5 \%)$ while other $146(63.5 \%)$ were alive within 24 hours of admission. According to APACHE-Il score, $84(36.5 \%)$ cases had $>11.5$ score and rests of 146(63.5\%) had APACHE-II $\leq 11.5$. The sensitivity, specificity, PPV, NPV and diagnostic accuracy of APACHE-II was 89.16\%, 93.2\%, 88.1\%, 93.84\% and $91.74 \%$. When data was stratified over age, gender and injury duration we found significant association of APACHE-II score and in hospital mortality, $\mathrm{p}$ value $<0.001$. Table-I,II,III.

\section{DISCUSSION}

Trauma is a major killing factor in young patients in industrialized and developing world. It has become the modern epidemic in young people. Although traffic safety and occupational safety measures have been improved and implemented but still trauma remains the most common cause of death despite advances in pre-hospital and inhospital trauma care.

To decrease the preventable deaths, scoring systems are commonly used all over the world. Assessment of severity of a disease or illness offers a lot of advantages to health care providers. Some of these advantages include patient outcome prediction, treatment efficiency and improvement of therapeutic and preventive measures. $^{7}$

Various tools and scoring systems have been used not only to predict mortality and morbidity in medical conditions but also in preoperative consent and prediction of mortality or survival after major trauma. Some of these include Acute Physiology And Chronic Health Evaluation (APACHE-II), APACHE-IV, Trauma Injury Severity Score(TRISS), Injury Severity Score(ISS) and Sequential Organ Function Score(SOFA). ${ }^{8-15}$

\begin{tabular}{|c|c|c|c|c|c|}
\hline \multirow{2}{*}{\multicolumn{3}{|c|}{ Age Groups (years) }} & \multicolumn{2}{|c|}{ Hospital Outcome } & \multirow{2}{*}{ P-Value } \\
\hline & & & \multirow{2}{*}{$\begin{array}{c}\text { Mortality } \\
42(87.5 \%)\end{array}$} & \multirow{2}{*}{$\begin{array}{c}\text { Alive } \\
2(2.4 \%)\end{array}$} & \\
\hline $18-40$ & APACHF \| score & $>11.5$ & & & $<0.001$ \\
\hline \multirow{2}{*}{$41-60$} & \multirow{2}{*}{ APACHE II score } & $>11.5$ & $32(91.4 \%)$ & $8(12.5 \%)$ & \multirow{2}{*}{$<0.001$} \\
\hline & & $\leq 11.5$ & $3(8.6 \%)$ & $56(87.5 \%)$ & \\
\hline
\end{tabular}

Table-I. Comparison of apachi-II score and in-hospital outcome when stratified for age (years).

\begin{tabular}{|c|c|c|c|c|c|}
\hline \multirow{2}{*}{\multicolumn{3}{|c|}{ Gender }} & \multicolumn{2}{|c|}{ Hospital Outcome } & \multirow{2}{*}{ P-Value } \\
\hline & & & \multirow{2}{*}{\begin{tabular}{|l} 
Mortality \\
$45(88.2 \%)$
\end{tabular}} & \multirow{2}{*}{\begin{tabular}{c|} 
Alive \\
$8(8.3 \%)$
\end{tabular}} & \\
\hline Male & APACHF II croro & $>11.5$ & & & $<0.001$ \\
\hline \multirow{2}{*}{ Female } & \multirow{2}{*}{ APACHE II score } & $>11.5$ & $29(90.6 \%)$ & $2(3.9 \%)$ & \multirow{2}{*}{$<0.001$} \\
\hline & & $\leq 11.5$ & $3(9.4 \%)$ & $49(96.1 \%)$ & \\
\hline
\end{tabular}

Table-II. Comparison of apachi-II score and in-hospital outcome when stratified for gender.

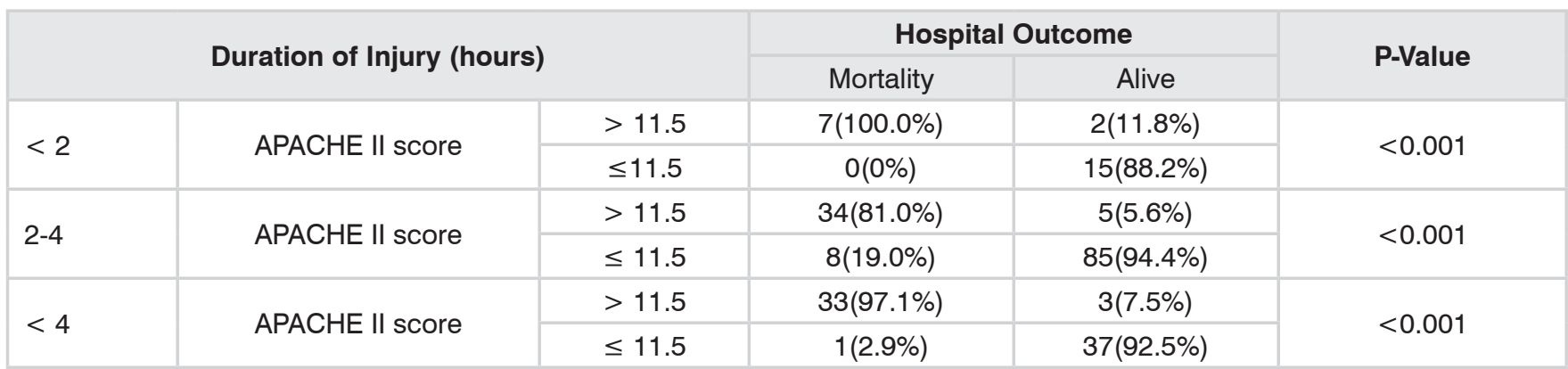

Table-III. Comparison of apachi-Il score and in-hospital outcome when stratified for duration of injury. 
All of these are in use in various setups especially in intensive care units depending upon the condition and simplicity of use in that particular unit. It is notable that some additional factors may contribute in final outcome. ${ }^{16-17}$ These scoring systems are very important tools for assessment of outcomes of traumatic illness and efficacy of trauma care units. In the past, main focus was on assessment of preventable mortality. With the passage of time the focus was shifted to tools which measure outcomes of patients after injury more accurately. These scoring systems have some strengths and weaknesses if used individually. The choice of scoring system varies according to setting, patients group, feasibility and applicability of scoring system in that particular setup.

APACHE system was introduced in 1981. It was used to classify severity of disease and prediction of future events in disease. In 1985, 12 physiologic measurements, age and previous health status were incorporated in APACHE I to develop APACHE II. It does not depend on prior therapeutic interventions or specific disease conditions. Despite newly developed scoring systems, APACHE II is still in common use for clinical research and audit owing to its easy use and consistency.

In 2016 a prospective study was conducted to observe the value of different prognostic scores used to predict mortality after admission. A total of 9549 patients were included.1276 patients (13.3\%) out of total patients died after admission in intensive care unit. Survivors and non survivors had different characteristics. ${ }^{18}$ In our study, we had highest mortality i.e. out of 230 cases in hospital mortality occurred in $83(36.1 \%)$ while other $146(63.5 \%)$ were alive within 24 hours of admission.

A study conducted in China on 98 geriatric trauma patients revealed that APACHE II may be more favorable in clinical decision making. In his study the overall mortality was $35.7 \%$. in this study GCS, RTS and APACHE II were significantly different in survivors and non-survivors. The abilities of APACHE II and TRISS to predict group mortality were examined by receiver operating characteristic curve analysis (ROC), two by two decision matrices, and calibration curve analysis. APACHE II had $0.898 \pm 0.032$ area under the curve whereas TRISS had $0.824 \pm 0.043$. With decision criterion of .5 the sensitivity, specificity and correct classification of APACHEll was $57.1 \%, 95.2 \%$, and $81.6 \%$ respectively concluding APACHE II a more specific score. ${ }^{19}$ These results are comparable in term of specificity to our study which had specificity of $93.2 \%$. But our study had more sensitivity.

In 2015 a study by Agarwal et al was carried out in orthopedic poly trauma patients in ICU of hilly terrain. It was a retrospective study and included 95patients .Sensitivity of APACH II was 90.91\% whereas specificity was $72.50 \%$. The sensitivity in this study is comparable to our study however it had a lower specificity. He also compared with TRISS and concluded that APACHE II is far better than TRISS in prediction of survival especially if calculated at the time of admission. ${ }^{20}$

\section{CONCLUSION}

According to the findings of this study, we found that APACHE II is highly accurate for prediction of hospital mortality with high sensitivity, specificity, PPV, NPV and diagnostic accuracy as $89.16 \%$, 93.2\%, 88.1\%, 93.84\% and 91.74\%. Using APACHE II in future we can devise an efficient treatment plan for poly trauma patients to reduce the probability of hospital mortality.

Copyright $(28$ Mar, 2020.

\section{REFERENCES}

1. Williams NS, Connell PR, Mc Caskie AW. editors. Bailey \& Love's short practice of surgery. $27^{\text {th }}$ ed. Florida: Taylor \& Francis group; 2018.p.310-21.

2. Traffic accidents annual. 2017-18: Pakistan Bureau of Statistics; http://www.pbs.gov.pk/content/trafficaccidents-annual.

3. Giannoudis PV, Giannoudis VP, Horwitz DS. Time to think outside the box : Prompt-Individualized-Safe Management (PR.I.S.M) should prevail in patients with multiple injuries. Injury 2017; 48(7)p.1279-82. 
4. Cernea $D$, Novac $M$, Drăgoescu $P$, Stănculescu $A$, Duca L, Al-enezy AA, et al. Polytrauma and Multiple Severity Scores. Current health sciences journal 2014; 40(4):244-8.

5. Edipoglu IS, Dogruel B, Dizi S, Tosun M, Cakar N. The association between the APACHE-II scores and age groups for predicting mortality in an intensive care unit: A retrospective study. Romanian Journal of Anaesthesia and Intensive Care 2019; 26(1); p.53-58.

6. Halim DA, Murni TW, Redjeki IS. Comparison of APACHE II,SOFA, and Modified SOFA scores in predicting mortality of surgical patients in intensive care unit at Dr. Hasan Sadikin General Hospital. Crit Care Shock 2009; 12(4):157-69.

7. Aminiahidashti $\mathrm{H}$, Bozorgi $\mathrm{F}$, Montazer $\mathrm{SH}$, Baboli M, Firouzian A. Comparison of APACHE II and SAPS II scoring systems in prediction of critically III patients' outcome. Emergency (Tehran, Iran). 2017; 5(1):e4.

8. Ghorbani M, Ghaem H, Rezaianzadeh A, Shayan Z, Zand F, Nikandish R. A study on the efficacy of APACHE-IV for predicting mortality and length of stay in an intensive care unit in Iran. F1000 Research. 2017; 6:2032.

9. Saleh A, Ahmed M, Sultan I, Abdel-lateif A. Comparison of the mortality prediction of different ICU scoring systems (APACHE II and III, SAPS II, and SOFA) in a single-center ICU subpopulation with acute respiratory distress syndrome. Egyptian Journal of Chest Diseases and Tuberculosis. 2015; 64(4):843-848.

10. Jentzer JC, Bennett C, Wiley BM, Murphree DH, Keegan MT, Gajic O, Wright RS, Barsness GW. Predictive value of the sequential organ failure assessment score for mortality in a contemporary cardiac intensive care unit population. Journal of the American Heart Association. 2018 Mar 10;7(6):e008169.

11. Eamer G, Al-Amoodi M, Holroyd-Leduc J, Rolfson D, Warkentin L, Khadaroo R. Review of risk assessment tools to predict morbidity and mortality in elderly surgical patients. The American Journal of Surgery. 2018; 216(3):585-594.

12. Yalcin M, Godekmerdan E, Tayfur K, Yazman S, Urkmez M, Ata Y. The APACHE II score as a predictor of mortality after open heart surgery. Turkish Journal of Anesthesia and Reanimation. 2019; 47(1):41-47.
13. Huang Y, Chen J, Zhong S, Yuan J. Role of APACHE II scoring system in the prediction of severity and outcome of acute intracerebral hemorrhage. International Journal of Neuroscience. 2015; 126(11):1020-1024.

14. Lee H, Yoon S, Oh SY, Shin J, Kim J, Jung CW, Ryu HG. Comparison of APACHE IV with APACHE II, SAPS 3, MELD, MELD-Na, and CTP scores in predicting mortality after liver transplantation. Scientific reports. 2017 Sep 7;7(1):1-0.

15. Zhang XM, Zhang WW, Yu XZ, Dou QL, Cheng AS. Comparing the performance of SOFA, TPA combined with SOFA and APACHE-II for predicting ICU mortality in critically ill surgical patients: A secondary analysis. Clinical Nutrition. 2020 Jan 22.

16. Nielsen A, Thorsen-Meyer $H$, Belling $K$, Nielsen A, Thomas C, Chmura $P$ et al. Survival prediction in intensive-care units based on aggregation of long-term disease history and acute physiology: a retrospective study of the Danish National Patient Registry and electronic patient records. The Lancet Digital Health. 2019; 1(2):e78-e89.

17. Li G, Thabane L, Cook DJ, Lopes RD, Marshall JC, Guyatt G, Holbrook A, Akhtar-Danesh N, Fowler RA, Adhikari NK, Taylor R. Risk factors for and prediction of mortality in critically ill medical-surgical patients receiving heparin thromboprophylaxis. Annals of intensive care. 2016 Dec 1;6(1):18.

18 Ho KM, Williams TA, Harahsheh Y, Higgins TL. Using patient admission characteristics alone to predict mortality of critically ill patients: A comparison of 3 prognostic scores. J Crit Care 2016; 31(1):21-5.

19. Lu J, Chen R, Tang L, Yin H, Shi X, Wu M et al. Comparison of the prognostic effects of APACHE II score and the TRISS for geriatric trauma patients in the intensive care unit. Int J Clin Exp Med 2018; $11(9): 9646-53$.

20. Agarwal A, Agrawal A, Maheshwari R. Evaluation of probability of survival using APACHE II \& TRISS method in orthopaedic polytrauma patients in a tertiary care centre. J Clin Diagn Res 2015; 9(7):RC01RC4. 


\begin{tabular}{|c|c|c|c|}
\hline \multicolumn{4}{|c|}{ AUTHORSHIP AND CONTRIBUTION DECLARATION } \\
\hline Sr. \# & Author(s) Full Name & Contribution to the paper & Author(s) Signature \\
\hline 1 & Manzoor Qadir Joyia & Data collection. & Mrarg \\
\hline 2 & Mudassar Murtaza & Concept design, supervision of & \\
\hline 3 & M. Ansar Aslam & $\begin{array}{l}\text { study and manuscript writıng. } \\
\text { Data collection. }\end{array}$ & \\
\hline 4 & Fakhar Irfan & Author os resutls to and tables. & \\
\hline 5 & Hira Liaqat & Data analysis and statistics. & \\
\hline 6 & Ahmed Raza Naumani & $\begin{array}{l}\text { Collection and writing of } \\
\text { references. }\end{array}$ & \\
\hline
\end{tabular}

